\title{
Characterization of Ionized Maltooligosaccharides by Sodium Cation in MALDI-TOFMS Depending on the Molecular Size
}

\author{
Sung-Seen Choi" and Sung-Ho Ha \\ Department of Chemisiry and Carbohydrate Bioproduct Research Center, Sejong University, Seoul 143-747, Korea \\ "E-mail: sschoi(u)sejong.ac.kr. \\ Received Mav l, 2006
}

Key Words : Maltooligosaccharides, Ionization, MALDI-TOFMS, Molecular size

Carbohydrates are the most abundant and structurally diverse compounds found in nature. Unlike linear polymers such as proteins and nucleic acids, oligo- and polymeric carbohydrates can form branched structures because linkage of the constituent monosaceharides can occur at a number of positions. With such a wide range of structural types, carbohydrate analysis by mass spectrometry can involve a large number of techniques with no single melhod being ideal for all compounds. Flectron impact ionization, for example, is only applicable to the smaller molecules. Matrix-assisted laser desorption/ionization (MALDI), ${ }^{1-3}$ on the other hand, is more versatile because most compounds give signals in their native states. As with other types of mass spectrometry, $M \wedge L D I$ can provide valuable information on several aspects of structural analysis, such as the detemination of sequence, branching, and linkage. Saccharides are more difficult 1o analyze than proteins. The hydrophilic nature of oligosaccharides and the lack of a chromophore have presented problems for their analysis, particularly with respect 10 detection. In addition, the absence of a basic site inhibits protonation in MALDI mass spectrometry. Carbohydrates most often ionize by adduction of metal ions, usually sodium cation, with comparatively low elficieney. ${ }^{4.5}$

Molecular weight distributions of materials can be oblained using MALDI mass spectrometry. ${ }^{6-1)}$ In order to measure accurate molecular weight distributions of an analyte, ionization efficiencies of all molecules in the analyte must be corrected. Several rescarches ${ }^{10-13}$ reported that the ion abundanees of carbohydrates were varied with the molecular size, but the detailed study and discussion have not been reported. In the present work, we investigated the variation of ionization efliciency of maltooligose with its size. The sample was ionized in the presence of sodium ion. Coneentrations of the maltooligose and sodium ion were varied. Fragmentation of the $[\mathrm{M}+\mathrm{Na}]^{-}$, where the $\mathrm{M}$ is maltooligosaccharide, was also studied.

The mass spectra of the samples containing maltooligosaccharides, NaTFA, and 2,5-DHB are composed of the matrix-related ions and the maltooligose-related ions as shown in Figure 1. The m/z 137, 154, 155, and 177 can be assigned to $[\mathrm{m}-\mathrm{OH}]^{+}, \mathrm{m}^{+},[\mathrm{m}+\mathrm{H}]^{-}$, and $[\mathrm{m}+\mathrm{Na}]^{-}(\mathrm{m}=2,5-$ DHB), respectively. The $m / x, 537,689,851,1013$, and 1175 are assigned to $[\mathrm{M}+\mathrm{Na}]^{+}$ions for $\mathrm{M}=$ maltotriose, maltoktraose, maltopentaose, maltohexaose, and maltoheplasose,

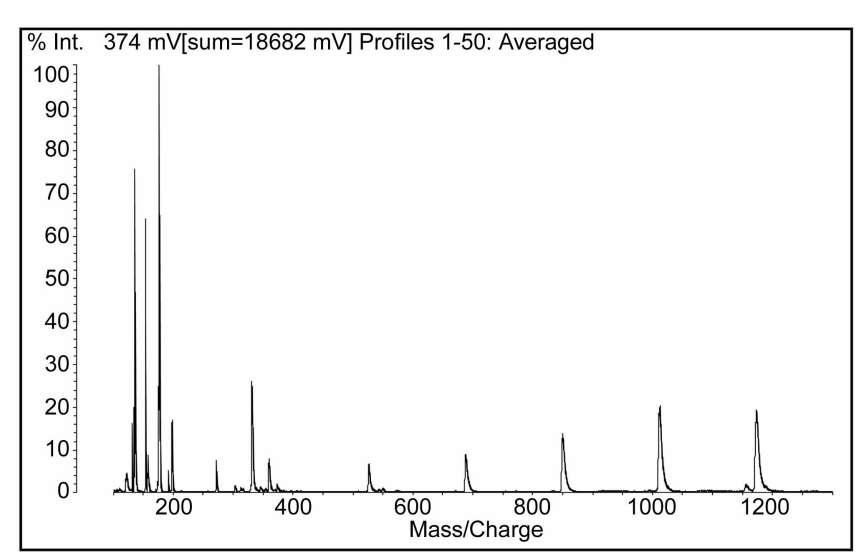

Figure 1. MALDI-TOF mass spectrum of $0.01 \mathrm{M}$ maltooligoses and $0.01 \mathrm{M}$ NaTFA.

respectively. The peak intensity of $[\mathrm{M}+\mathrm{Na}]$ increases notably until the hexamer by inereasing the maltooligose size and then decreases. (of the four matrix-related ions, the [ $\mathrm{m}+\mathrm{Na}$ ] is the most abundant one and the second is the $\mid \mathrm{m}$ - OJl'. The peak intensitics of the $\mid \mathrm{M}+\mathrm{Na}$ lons were normalized with [m+ $\mathrm{Na} \mid$ and $\mid \mathrm{m}-\mathrm{OH}]$ to investigate the differenee in the ionization efficiencies of the maltooligoses. Figures 2,3 , and 4 show variations of the $[\mathrm{M}+\mathrm{Na}]^{+} /[\mathrm{m}+$ $\mathrm{Na}]^{+}$and $\left[\mathrm{M}+\mathrm{Na}^{+} /[\mathrm{m}-\mathrm{OH}]^{+}\right.$ratios as a function of the molecular size for the NaTFA concentrations of 0.001 , 0.005 , and $0.01 \mathrm{M}$, respectively.

By increasing the molecular size, the $[\mathrm{M}+\mathrm{Na}]^{+} /[\mathrm{m}+\mathrm{Na}]^{-}$ and $[\mathrm{M}+\mathrm{Na}]^{+} /[\mathrm{m}-\mathrm{OH}]^{+}$ratios increase continuously until the hexamer. The ion intensity ratios also increase with increse of the maltooligose conecntration. The enhaned ion intensity with the molecular size may be due to the stable ion-molecule complex formed between sodium cation and maltose. The sodium cation can be casily adducted to hydroxyl groups of the maltose. The ion-molecule complex with two hydroxyl groups of the neighboring maltose units is more stable than that with only one. ${ }^{1+4}$ By increasing the maltooligose size, the ion-molecule complex with two hydroxyl groups of the neighboring units will increase (Scheme 1).

For the maltoheptasose, the $[\mathrm{M}+\mathrm{Na}-18]^{+}$ion was also detected. The $[\mathrm{M}+\mathrm{Na}-18]^{-}$ions were not observed in the maltotriose to maltopentaose and it was detected only by 


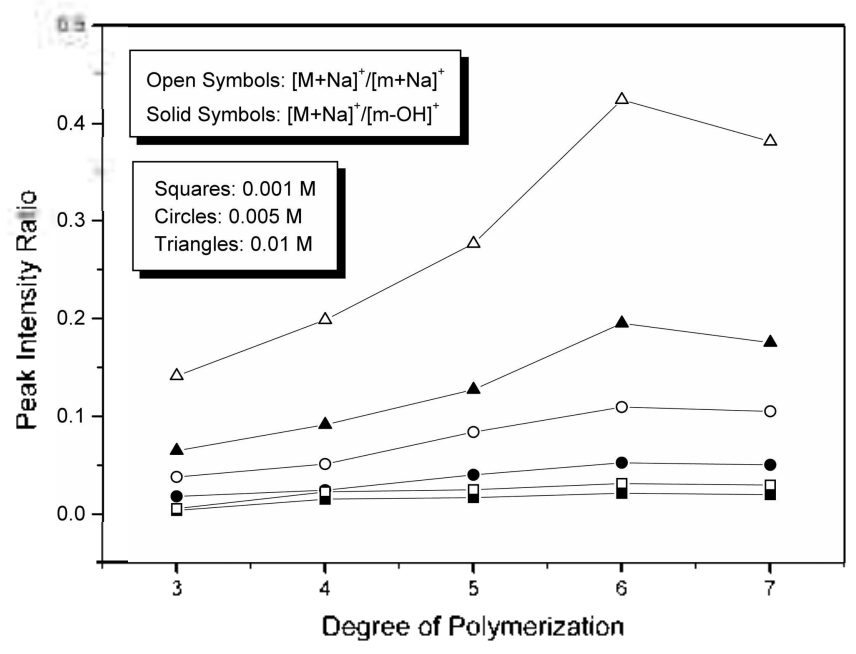

Figure 2. Variations of the peak intensity ratios as a lunction of the degree of polymerization for the NaTF $\Lambda 0.001 \mathrm{M}$. Squares, circles, and triangles indicate the maltooligoses concentrations of $0.00 \mathrm{I}$, 0.005 , and $0.01 \mathrm{M}$, respectively. Open and solid symbols stand for the ratios of $[\mathrm{M} \mid \mathrm{Na}]^{\prime} /[\mathrm{m} \mid \mathrm{Na}]^{\prime}$ and $\left.[\mathrm{M}+\mathrm{Na}]^{\prime} / \mathrm{m}-\mathrm{Ol}\right]^{\prime}$ respectively, where $m$ and $M$ are matrix and maltooligose, respectively.

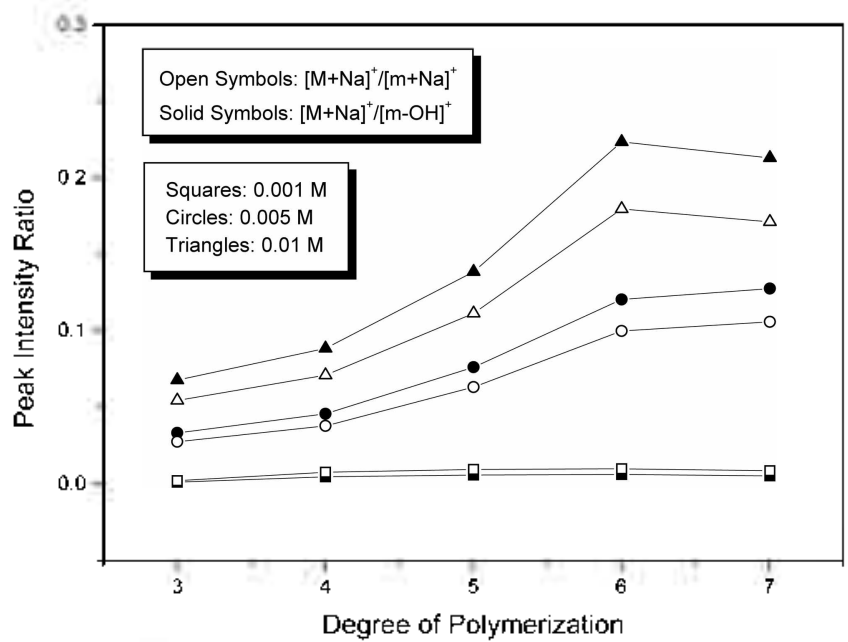

Figure 3. Variations of the peak intensity ratios as a lunction of the degree of polymerization for the NaTF $/ 0.005 \mathrm{M}$. Squares, circles, and triangles indicate the maltooligoses concentrations of 0.001 , 0.005 , and $0.01 \mathrm{M}$, respectively. Open and solid symbols stand for the ralios of $[\mathrm{M}$ । $\mathrm{Na}] /[\mathrm{m} \text { । } \mathrm{Na}]^{\prime}$ and $[\mathrm{M}$ । $\mathrm{Na}] /[\mathrm{m}-\mathrm{Ol}]^{\prime}$ respectively, where $m$ and $M$ are matrix and maltooligose, respectively.

trace in the maltohexaose. The ratios of $[\mathrm{M}+\mathrm{Na}-18]^{-} /[\mathrm{M}+$ $\mathrm{Na}^{-}$are 0.084 and 0.023 for maltoheptaose and maltohexaose, respectively, when the concentrations of sodium cation and maltoligoses are 0.0$] \mathrm{M}$. The $[\mathrm{M}+\mathrm{Na}-18]^{-}$ion can be assigned to $\left[\mathrm{M}+\mathrm{Na}-\mathrm{H}_{2} \mathrm{O}\right]^{+}$formed from the $[\mathrm{M}+\mathrm{Na}]^{+}$ion by dehydration. The maltooligose has helix structure when its size is large enough. ${ }^{15}$ The hexamer has one turn helix structure as shown in Scheme 2 and the two teminal monomers of the heptamer are overlapped. The sodium cation can be located between the terminal units of the maltoheptaose. Dehydration reaction can occur between two hydroxyl groups of 3-and 6-carbons of the maltoheptaose as

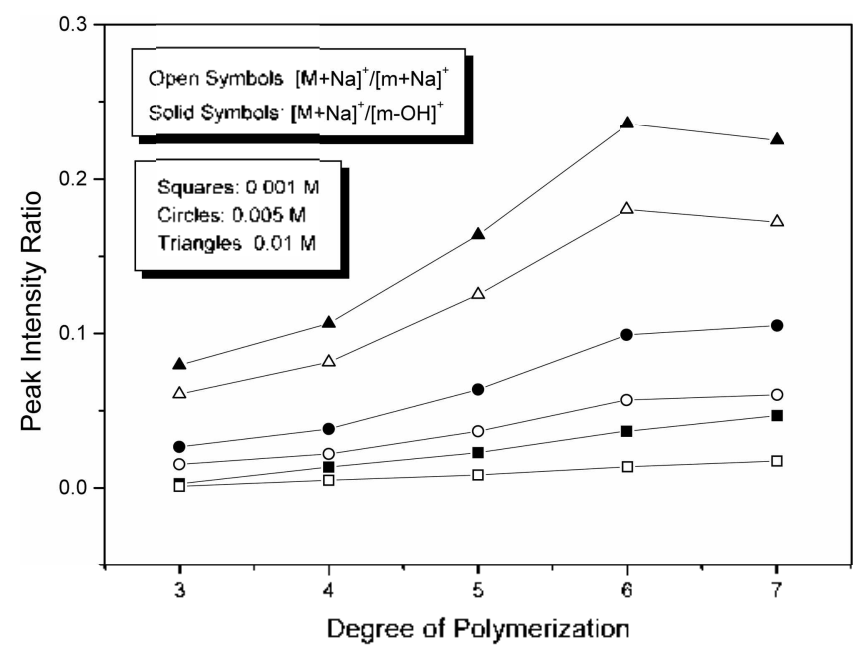

Figure 4. Variations of the peak inlensily ratios as a funclion of the degree of polymerization for the NaTF $\triangle 0.01 \mathrm{M}$. Squares, circles, and triangles indicate the maltooligoses concentrations of 0.001 , 0.005 , and $0.01 \mathrm{M}$. respectively. Open and solid symbols stand for the ratios of $[\mathrm{M}+\mathrm{Nal}] / \mathrm{m}$ । $\mathrm{Na}]^{\prime}$ and $[\mathrm{M} / \mathrm{Na}]^{\prime} /[\mathrm{m}-\mathrm{OII}]^{\prime}$ respectively, where $m$ and $M$ are matrix and maltooligose, respectively.

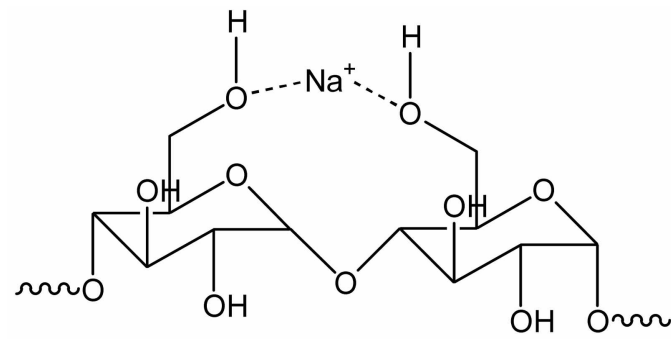

Scheme 1. Sodium cation-maltose complex.

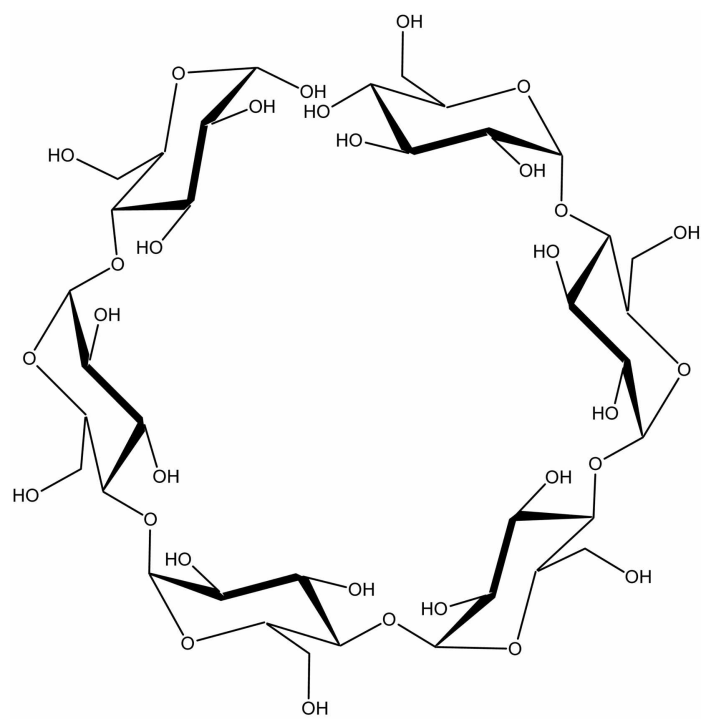

Scheme 2. Structure of maltohexaose.

shown in Scheme 3. Further study for the dehydration reaction is needed.

From the experimental results, it can lead to a conclusion 

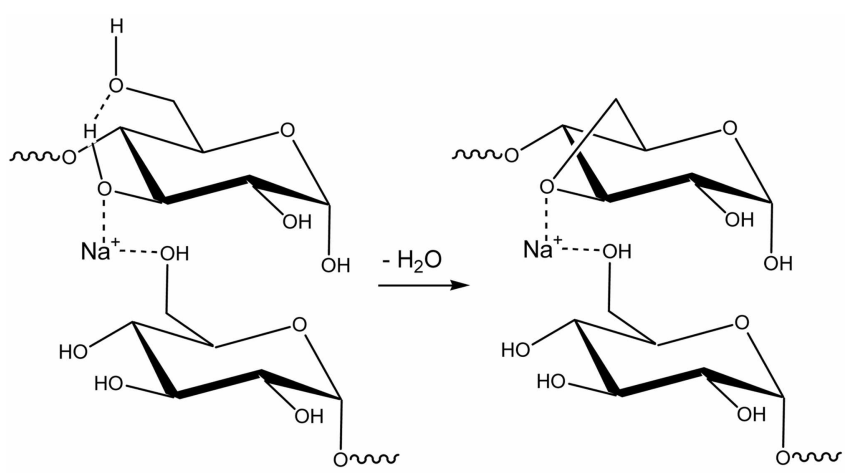

Scheme 3. Plausible mechanism for formation of I maltoheptaose + $\left.\mathrm{Na}-\mathrm{H}_{2} \mathrm{O}\right]^{\prime}$.

that ionization efficiency of maltooligose is varied with the molecular size and the difference becomes larger as the sample concentration increases.

\section{Experimental Section}

Maltotriose, maltotetraose, maltopentaose, maltohexaose, and maltoheplaose purchased from Aldrich $\mathrm{Co}$, were employed as maltooligosaccharides. 2,5-Dihydroxybenzoic acid (2,5-DHB) and sodium trifluoroacetate (NaTFA) purchased from Aldrich Co, were used as matrix and cationizing agent, respectively. The matrix, maltooligosaccharides, and cationizing agent were dissolved in distilled water. The malteoligosaccharides (trimer-heptamer) with the same moles were dissolved. Concentration of $2,5-\mathrm{DHB}$ was constant of $0.1 \mathrm{M}$ and concentrations of NaTFA were varied of $0.001 \mathrm{M}, 0.005 \mathrm{M}$, and $0.01 \mathrm{M}$. Concentrations of maltooligose mixture of the trimer-heptamer were also varied of $0.001 \mathrm{M}, 0.005 \mathrm{M}$, and $0.01 \mathrm{M}$. The maltooligoses, cationizing agent, and matrix solutions were mixed (maltooligoses : cationizing reagent : matrix $=1: 1: 5$ ). The mixed solution of $2 \mu \mathbf{I}$. was spotted onto the sample plate and dry.

MAI.DI mass spectra were obtained with Axima-I.NR MAI_DJ-TOFMS (Kratos-Shimadzu Co. of Japan). Ions were produced by irradiation of the sample with nitrogen laser $(337 \mathrm{~nm})$. Profiling of product ions was achieved in the positive mode using linear TOF. The aecelerating voltage was $20 \mathrm{kV}$. The sum of 50 shots was collected for each spectrum.

\section{References and Notes}

I. Cha, S.; Kim, H.-J. Bull. Kor: Chem. Soc: 2003, 24, 1308.

2. Park, S.-I.; Park, D.-H.; Sul, S.; Oh, S; Park, I.-S; Chung, D. S.; Kim, II.-I.: Kim, M.-S; I.ec, S.-W. Bthl. Kor. Chem. Soc. 2004, 25. 1791 .

3. Moon, J. H.; Yoon, S. H.; Kim, M. S. Bull. Kon Chem. Soc 2005. 26.763 .

4. Harvey, D. I. Mass Spectrom. Ron: 1999, /8, 349.

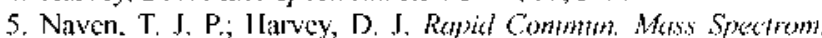
1996. 10,829

6. Rashidzadeh, H.; (ino, B. Anof. Chem. 1998, 70, I3I.

7. Tatro, S. R.; Baker, G. R.; Fleming, R.; Harmon, J. P. Polwner $2002,43,2329$.

8. van Rooij, G. J.; Boon, J. J.; Duursina, M. C.; Heeren, R. M. A. Int. J. Mass Spectrom. 2002, 221, 191.

9. I.iu. J.; I.ocwe, R. S.; McCullough, R. D. Merromolectles 1999, 32,5777 .

10. Karmaier, T.; Roth, S.: 7.app, J.: Marding, M.; Kuhn, R. Fresenints J. Anal Chem. 1998, 361,473.

11. Wang, 1, Jiang. G; Vasanthan, T; Sporns, P. Starch 1999, 5/, 243.

12. Lattova, E.: Perreault, H. J. Chromatgr. B 2003, 793, 167.

13. Bashir, S.; Derrick, P. J.; Critehley. P, Gates, P. J.; Staunton. J. Eutr. J. Mass Spectrom. 2003, 9,61.

14. Ohanessian, (i. Int. J. Moss Spectrom. 2002, 219.572.

15. Davis, H.: Skrzypek, W.; Khan. A.J. Polym. Sci. 1994, 432, 2267. 